Challenging authenticity: fakes and forgeries in rock music

Chris Atton

Chris Atton

Professor of Media and Culture

School of Arts and Creative Industries

Edinburgh Napier University

Merchiston Campus

Edinburgh EH10 5DT

T 01314552223

E c.atton@napier.ac.uk

8210 words (exc. abstract) 


\section{Challenging authenticity: fakes and forgeries in rock music}

\section{Abstract}

Authenticity is a key concept in the evaluation of rock music by critics and

fans. The production of fakes challenges the means by which listeners evaluate the authentic, by questioning central notions of integrity and sincerity. This paper examines the nature and motives of faking in recorded music, such as inventing imaginary groups or passing off studio recordings as live performances. In addition to a survey of types of fakes and the motives of those responsible for them, the paper presents two case studies, one of the 'fake' American group the Residents, the other of the Unknown Deutschland series of releases, purporting to be hitherto unknown recordings of German rock groups from the 1970s. By examining the critical reception of these cases and taking into account ethical and aesthetic considerations, the paper argues that the relationship between the authentic (the 'real') and the inauthentic (the 'fake') is complex. It concludes that, to judge from fans' responses at least, the fake can be judged as possessing cultural value and may even be considered as authentic. 


\section{Challenging authenticity: fakes and forgeries in rock music}

Little consideration has been given to the aesthetic and cultural significance of the inauthentic through the production of fakes in popular music, except for negatively critical assessments of pop music as 'plastic' or 'manufactured' (McLeod 2001 provides examples from American rock criticism). In this paper I show how faking may not only be an exercise in deceit for commercial ends or as a musical joke, but how it may also contribute to our understanding of listeners' aesthetic pleasures and ethical assessments. The performance of pretence and deceit inevitably speaks to questions of authority and originality, and can reveal through the discourses that surround them new ways of paying attention to the constructedness of popular music. The paper begins with a theoretical exploration of the notion of authenticity in rock music, before going on to present an overview of types of faking in rock music, specifically through the invention of fake musicians and groups, and through the presentation of studio recordings as live recordings (and vice versa).

The bulk of the empirical work presented here focuses on two examples that bring together fake groups and fake recordings: the American group the Residents and a collection of German groups on the Pyramid label. These cases have been chosen in part for their longevity. The Residents have been releasing records since the early 1970 s and are still active today. The Pyramid groups supposedly recorded in the mid-1970s, though their work was not released until twenty years later. In both cases, uncertainty and controversy still surround their work. Critics and fans continue to argue over 
the authenticity of the groups and their work. Are these fake groups? Do they have an existence beyond their presentation in recorded form? What does it

mean to speak of 'real' or 'fake' groups? Is a fake group capable of producing authentic music? Before we are able to address questions such as these asked by listeners, we must first address the notion of authenticity as a central concept in the reception of rock music.

\section{Authenticity in rock music}

Discourses of authenticity have an enduring significance in popular music, both within cultures of reception (that is, amongst fans and music critics) and within the academy. Arguments over what constitutes authentic music and authentic performance may be found across many genres of contemporary popular music. Lindberg et al. (2005, p. 45) consider genres as diverse as 'folk music, 1960s soul, grunge, old school rap' as sites where debates over authenticity are deployed as a means of evaluating musical performances. Though they offer no evidence or argument, Barker and Taylor (2007, p. xi) controversially assert that it is possible to evaluate entire genres as 'transparently "inauthentic"' (they cite heavy metal, techno and show tunes). Frith (1996, p. 71) claims that 'fans can distinguish between authentic and inauthentic Eurodisco' and in doing so raises questions about artifice, technology and authority that lie at the heart of authenticity discourses, questions to which we shall return.

It is in rock music that we find strong and enduring claims about authenticity. Robert Walser (1993, pp. 129-130) finds that in 'the journalism of heavy 
metal, the most heated debates are over "authenticity". For the editors of Rock Over The Edge

it is as if rock would cease to exist without the opposition of "real" and "fake" musics to underwrite it (and, of course, it would cease to exist to the degree that "rock" is supposed to be the name given to "authentic" music).

(Beebe, Fulbrook and Sanders 2002, p. 3)

Beebe, Fulbrook and Sanders connect the authentic to the 'real' and suggest (though they do not explore the implications themselves) that one route to understanding the significance of the authentic in rock music is to examine the dialectic between the real and the fake. Such an examination requires that we attend to the authentic in two interrelated ways: as a matter of aesthetics and as an ethical practice. We need to keep in mind that aesthetics and ethics in cultural discourse are likely to become entangled, yet it should be possible to examine them separately to some degree. Moore (2001, p. 199) draws our attention to both their distinctiveness and their connectedness when he argues that the authentic relates to intimacy and immediacy (the aesthetics of performance) and is also 'what we trust because it issues from integrity, sincerity, honesty' (an ethical practice).

Grossberg (1992, p. 589) writes of rock music articulating 'private but common desires, feelings and experiences into a shared public language', an argument that is developed by Moore, who argues that it is possible to think of 
authenticity as a practice of communicative integrity that, in rock music at least, challenges the 'commercial enterprise' of rock music and makes it possible for performers and fans alike to engage with the products of mass media without, in the language of rock criticism, 'selling out'. Rather than collapse all aspects of authenticity into a single mode of communication, he posits three modes that equate to the three persons of English verbs. Firstperson expression (I, me, mine) aims to convince an audience that performers are communicating their own thoughts and feelings directly to that audience. Second-person communication (you, yours, singular or plural) speaks to the experience of the audience themselves, 'conveying the impression... that their experience is validated' (Moore 2001, p. 200). Third-person communication (his, hers, theirs) is concerned with what we might call 'channelling', where a performer presents the style or content of another (Moore gives the example of Eric Clapton performing the songs of Robert Johnson). To these three modes Adam Behr (2015) has added a fourth, that of the first-person plural (we, ours) or 'collective' authenticity. This mode considers the musical group or band as a collective agent, extending the notion of authenticity from the performance of expression by accounting for the social context in which the music is produced. Behr brings together creativity and social relations in an argument for authenticity that moves away from the singular modes and recognises the significance of group dynamics in collaborative composition and performance in popular music. As we shall see later, the presentation of the group is central to many instances of fakes and forgeries in popular music. 
What these modes have in common is not an actual demonstration of immediacy or unmediated communication (even folk music has not been immune to mediation, whether technological, cultural or economic). Nor is there a requirement for the performance to be the outcome of the lived experience of either the performer or the audience. What matters is how convincing the performance is to an audience, how readily that audience can believe in the performance, how trusting they are of the performer. Part of that trust might lie in the socioeconomic background of the performer, or at least a convincing account of that background. In rock, a musician's educational background is useful to such a story if it is working-class; grammar schools and universities are suspicious, or the province of progressive rock; comprehensive schools and art colleges less so. Formal musical education might be similarly unconvincing in personal narratives of authenticity. In other cases, authenticity might proceed from the musical materials themselves, where blues-derived structures are considered more authentic than those derived from classical music or from jazz. In terms of instrumentation, we might look for the authentic in the 'classic rock' formation of guitar, bass, drums and (the untrained) voice. Finally, the 'truth' of a performance in a song-based popular culture (which is, after all, the dominant practice of rock music), comes from lyrics that present what Frith (1983, p. 45) terms the 'subjective vision' of the performer, which is seen not only as part of a tradition but also as departing from that tradition to make a music that is original. 
Taken together these elements make it possible for an audience to believe in performers and their work as authentic, to the degree that the work appears to accord with the personality of the performer, the views and experiences of the audience, the transmission of an 'inherited' performance (which is itself considered authentic) or the communal experience of performer and audience alike. In all these cases the 'real' is found in the performance and reception of conviction, where integrity matters to the extent that an audience is convinced it is being told the truth. There is, however, in addition to the two aspects of the authentic at play here - the aesthetic and the ethical a third element, that of historical narrative. It is perhaps more useful to speak of this as aetiology; that is, as an account of the history of production of a performance, which would include not only information about its performers, but also details of the technical, economic and cultural circumstances that led to the production of the performance.

\section{Defining fakes and forgeries}

Before we can examine the nature of fakes in rock music and, importantly, their cultural significance, we must first establish some terms of reference. In what follows I shall not be considering the presentation of lyrical content as an indicator of a performer's autobiography. As Barker and Taylor (2007) point out, the presence of specific autobiographical information in popular song is rare (they cite Jimmie Rodger's 'T.B. Blues'). Moreover, even where songs are written in the first person, they are most often in character and in this respect resemble folk songs, 'songs that anyone could sing' (p. 129). What matters in these cases is not the personal truth of an experience, but how 
convincing the expression of the experience appears to an audience. In discussing the significance of the causal history of a work of art (and by extension a musical performance), Janaway argues that, whilst we as an audience might include, for example, 'facts about an artist's mental states' in order to ascribe value to an artist's work, any 'interesting and plausible story' might suffice: for the purposes of interpretation we are not terribly concerned to establish the causal history of actually occurring aims, intentions, beliefs and feelings' (1997, p. 12).

It would therefore make little sense to argue that a performance is fake if, and only if, an audience is not convinced that the content is a true expression of personal experience. It may be that another audience at another time and location is convinced, or that they are satisfied to provide for themselves an 'interesting and plausible story', in which case we would need to render the notion of fake so contingent as to effectively deny the existence of a fake performance per se. Instead we need to work with a definition of fake that is stable, one that enables analysis in varying cultural and social contexts.

Hunter Steele provides a useful definition that takes account of the aetiology of a performance, one that is not dependent on a highly relativised view that would render the fake unstable and subject to chance. Steele argues that a work of art is a fake 'if and only if it is a work falsely purporting to have a given history of production' (1977, p. 258). The forgery, on the other hand, falsely purports to have a given history of production 'which is actually possessed by an original work' (ibid.). Steele is interested in examining the aesthetic value 
of fake and forged musical performances. To do so he develops Nelson Goodman's (1968) argument that some arts (chiefly painting) are autographic, whereas others (literature and music) are allographic. That is to say, a forged painting is possible because it is possible to produce an exact copy of an existing, unique work and claim its history of production as identical with that of the original work. In the case of the literary or musical work, such a claim is incoherent, since both forms rely on a notation. To copy James Joyce's Ulysses in its published form would be simply to produce an edition identical to the one being copied. (Whilst the original might exist as an autograph manuscript, we do not consider literary or musical works as existing in a unique form, unlike paintings.).

In discussing the possibility of forgery in music, both Goodman and Steele use examples from classical music, where the work is considered to be the score. As with literature, to present a copy of an already-published score is to present the score itself; it makes no sense to speak of forgery in such cases. We may argue, however, that if we take into account the paratextual material of a novel or a score (its copyright page, its publishing data, its covers), then we are presented with a forgery of a specific edition of a novel or a score, more accurately a replica. In the context of popular music, forgeries as replica versions of rare or classic albums have for decades been the province of the bootlegger. As vinyl enjoys a resurgence, what we might term 'official' forgeries have become popular, often produced by the record companies that first released them. 
In terms of rock music (or indeed, any form of popular music), I am defining 'fake' as a commercially released recording that falsely claims to possess a given history of production, which may include claims about musicians, the music and the circumstances of the recording. In the second half of this paper I will examine questions of aesthetic value and cultural significance as revealed by the critical reception of fans and critics to two types of fake: the American group the Residents; and a particular set of recordings the provenance of which is highly contested, the Unknown Deutschland series of CD releases and related LP reissues. At this stage, however, I offer some briefer examples to demonstrate the range of fakes in recorded rock music.

\section{Fakes in rock music}

The most common type of fake is that which purports to have been recorded live in concert. Perhaps the most notorious of these is Thin Lizzy's Live and Dangerous (1978). Tony Visconti, the album's producer, has claimed that there were so many overdubs made in the studio that the only parts of the live recordings left untouched were the drums and the audience response. Even the latter, Visconti claims, was subject to alteration: in one instance (during the song 'Rosalie'), Visconti 'plays' the audience's applause by making a tape loop of applause and triggering it with a keyboard, to emulate the sound of an audience clapping in time (Visconti 2012). More extravagant still, though less technologically sophisticated, is the Seeds' 1968 album, Merlin's Music Box, supposedly recorded live at the eponymous Los Angeles venue. Though not known at the time of release, it is now generally acknowledged that the album was recorded entirely in the studio, with audience reaction overdubbed and a 
fake introduction to the group recorded by the venue's resident DJ. In both cases, the aim appears to be to produce an album that captures the spirit of live performance and that either corrects errors in performance or recording (Thin Lizzy) or that seeks an 'as live' studio recording that captures a group more spontaneously than a more studied studio performance (the Seeds). The fake live album has also been used for humorous ends. The Scottish progressive rock group Chou Pahrot's Live album (1979) was not recorded live at all, but has an overdubbed stadium-sized audience whose frantic and tumultuous approbation is quite out of proportion with the group's narrow fan base and the small venues where they played.

Frank Zappa transformed the combination of studio and live recordings into a longstanding method of working. He would often place solos recorded live into studio recordings of his compositions, as in 'Inca Roads' on his album One Size Fits All (1975). More elaborate are albums such as Weasels Ripped My Flesh (1970), where live and studio recordings are collaged to produce a series of songs and instrumental pieces. Unlike our earlier examples, however, the technique is not hidden: in the liner notes to Weasels Zappa meticulously details the sources of all the elements of each piece (including dates, concert venues and studios). King Crimson's 1974 album Starless and Bible Black is a rare example of live recordings presented as studio recordings. The liner notes state that the album was recorded at Air Studios in London, but only two full songs (and one half of a third) were studio recordings, the remainder coming from a recording made at Amsterdam's Concertgebouw, comprising mostly edits of improvisations, with audience 
reaction removed. At this period in the group's life, very little new material had been composed and, despite the musical quality of the improvisations, it might be argued that using extemporised performances is an efficient and relatively cheap way of completing an album (Smith 2001).

We now move from fake recordings to fake groups, the most well known of which is probably the Monkees, put together in the US in 1965 to capitalise on the success of the Beatles amongst teenagers and to emulate not so much the songwriting of Lennon and McCartney but the personae of the Beatles in their films A Hard Day's Night and Help!. The television series combined verbal and slapstick comedy with mimed performances. Whilst the group sang on their recordings, they did not play instruments (or perform their own songs) until the Monkees as a brand had been established and the group was able to argue for more artistic control. In this case, the fake group becomes a 'real' group as the members grow together and use their commercial success to assert their own authority. The Archies, whose one hit single 'Sugar, Sugar' enjoyed chart success in the US and the UK in 1969, were a much shorter-lived example of the fake group, existing publicly only as an animated cartoon, the actual group comprising unnamed session musicians.

More recently, Gorillaz also began life as a cartoon group in 1998, hiding the identity of its leader, Damon Albarn, who hoped that by establishing a fake group with its members' identities hidden, his new music would not suffer from comparison with his main group, Blur. Subsequently, the identity of Gorillaz was revealed and now performs as a conventional group, with guest 
musicians. In 2006, Dave Stewart (formerly of the Eurythmics) and songwriter Kara DioGardi released an album titled Make Believe under the name of Platinum Weird, which was supposedly recorded by a group of that name in 1974. John Fahey's first album, released in 1959, comprised performances under own his name on one side and on the other performances allegedly an obscure blues guitar player named 'Blind Joe Death', who taught Fahey to play the guitar (but who was actually Fahey himself); in part a joke, in part a homage to his influences and in part to give authenticity to his music - a type of third-person authenticity, where the third person is fictional. More obviously lighthearted in approach would be the many examples of modern studio recordings produced to sound like old recordings, complete with hiss, scratches and bumps typical of a 78rpm recording. Lol Coxhill's 1984 album Cou\$cou\$ opens with 'West Lawn Dirge/Just a Closer Walk with Thee', credited as the work of saxophonist Buck Funk (actually Coxhill himself), supposedly recorded in New Orleans in the 1920s. These examples adopt very different strategies from the widespread adoption of pseudonyms, often multiple pseudonyms by one performer, amongst electronica and electronic dance musicians, such as the Aphex Twin and Squarepusher. In these cases the impetus is closer to the practice of naming groups, rather than a desire towards fakery.

\section{The Residents}

The Residents provide the most complex example of a fake group. It is tempting to state that they are the longest-lived fake group, but given that their entire history is open to doubt, this would be a curious claim to make. The 
liner notes to their first album, Meet the Residents (1974) imply that the group was in existence at least in 1968, when 'they began collecting interesting and unusual tapes... [and] gained widespread notoriety for their [own] unusual recordings'. Allegedly they negotiated a contract with Warner Brothers some time between then and the release of their first album, as well as working with Philip 'Snakefinger' Lithman, formerly of British country blues group, Chilli Willi and the Red Hot Peppers. The group was promoted as a quartet, though no members were ever named and the membership of the group remains unknown. The group's management, the Cryptic Corporation, comprised four men who, it has been alleged, were also the Residents (Shirley 2015). For example, based on the vocal similarity between Homer Flynn, apparently now the only remaining member of the Cryptic Corporation, and the lead vocalist, known only as Randy, in the Residents' current formation, it has been argued that they are one and the same, though 'both' deny the claim (Lefebvre 2017). Still active today, and with a reputation that has seen the group's work housed in New York's Museum of Modern Art, the group now appear to have a fluid membership (perhaps it always did). The Residents have released almost 100 albums and continue to tour the world in theatrical presentations of their work, in contrast to their early years, where they refused to perform in public for over a decade.

Unlike the previous examples of fake groups, it is difficult to assess precisely the rationale behind the elaborate narratives and performances sustained by the Residents over five decades. Indeed, the notion of 'fake' in the case of the Residents is, if not open to question, at least open to complication. From 
the perspective of a proponent of authenticity, the group may well be considered fake, in its apparent desire to frustrate any attempts at examining precisely what its music, performances and recordings authenticate. It is better perhaps to consider the work of the Residents as displaying aspects of postmodernism in its presentation of a group identity that is fugitive, unstable and shifting, and where authenticity is already challenged. It is difficult to find a unitary purpose to the Residents, one that binds its interests in multiple identities and hybrid genres (the music ranges across many forms of rock and pop, as well as opera and theatre).

The group's enterprise may be considered as a shifting composite, a satire on popular music and commerce; it may be construed as an opportunity for a group to evolve without the constraints of publicity that comes from changes in line-up, and consequent questions of what or who constitutes the original (and authentic?) Residents; it may be an elaborate publicity stunt. When their records were first released in the UK in the mid-seventies, the group's anonymity and bizarre publicity photographs (dressed in radiation suits, in costumes made of newspapers and, most famously, in white tie and tails, each 'member' wearing a giant eyeball mask) brought them widespread coverage in the music press. A postmodern impulse may be seen at work in this play of identities, including the notion of anonymity, of no identity.

Despite self-evident publicity stunts such as refusing to release their second album until the group had forgotten about it, then releasing it only four years after it had allegedly been recorded (under the title Not Available), the group 
have enjoyed significant critical success. In his File under Popular, musician and theorist Chris Cutler devotes a full chapter to the group. He has also played with them on their Commercial Album and wrote one of the earliest feature articles on the group in the British music press.

Cutler's interpretation of the Residents never engages directly with the notion of the group as a fake. However, he does find in their work an intervention with authenticity, arguing that the Residents have little interest in selfexpression, preferring to present their music as part of a gesamtkunstwerk that is closer to film than recorded music, that focuses on dramaturgy, on the 'invocation of types' in which the group's anonymity is not merely a gimmick or a publicity stunt, but 'is not less a part of their work than the music itself. Their drama is acted out against the scenery of their own deliberately fabricated “being”' (Cutler 1985, p. 89). Working within the industry of popular culture, Cutler goes on, enables the Residents to use their fabricated identities as a commentary on the mythologies of rock's discourse of authenticity, with the group inviting the listener to become 'co-conspirator, a partner in a shared pretence' (p. 91). Rather than faking a group to deceive a gullible audience into believing an 'authentic' narrative, the Residents set out to challenge such a narrative, through constructing an absurdist version of the narrative. And yet, as Cutler emphasises, the group's work is to be taken seriously: he variously assesses it as 'iconoclastic', 'provoking', 'brilliantly executed' and 'powerful and subtle' (p. 105).

\section{Unknown Deutschland and the story of Pyramid Records}


My final, extended, example brings together both categories of fakes, fake groups and fake recordings. Or, rather, it presents what might be an entirely faked set of recordings made by groups that might have never existed. As we shall see, questions of identity and purpose similar to those we encountered with the Residents appear here, once again suggesting a postmodern impulse at work. In this case, however, the impulse behind the creative work is further complicated by uncertainties and arguments over the provenance of the recordings. The status of the recordings released on CD in 1996 by Virgin Records as three volumes of Unknown Deutschland: The Krautrock Archive purport to be samplers of obscure German rock groups from the mid-1970s, and compiled from LPs originally released on an equally obscure label, Pyramid Records. The controversy surrounding the recordings, the groups and the label might seem out of proportion to the significance and popularity of the music itself, but examining the arguments over the authenticity of the Unknown Deutschland project and, in particular, how critics and fans of German rock music have engaged in these arguments, offers a rich picture of how a discourse of authenticity can be played out, one that addresses the key concepts we encountered at the beginning of this paper: aesthetics and ethics, as well as questions about artifice, technology and authority.

The liner notes by Trevor Manwaring (who also compiled the series) that accompany the first volume of the Unknown Deutschland series read in their entirety: 
These recordings were made between 1972 and 1974 using studios in and around Cologne. They were originally produced for the Pyramid label in tiny quantities and mostly sold in art galleries and the like - this is probably why they have remained so obscure, even among 'experts'..... [interpunctio sic] until this release.

The 'Mad Twiddler' responsible for their existence also worked with Stockhausen, Can, the Cozmic [for Cosmic] Jokers and many more. Although memories are beyond repair in many cases the tapes remain to bear witness to this creative and anarchic scene.

(Manwaring 1996)

Apart from a list of personnel for each of the six groups appearing on the CD we have no further information. The three volumes feature recordings by eleven groups and one solo artist, none of whom, it seems, had been known to fans of German rock music before the release of the CDs. Since their release, however, full albums have appeared (on CD and vinyl) by some of the groups, including Cozmic Corridors (2017), Galactic Explorers (2017), Golem (1996, 2009 and 2017), the Nazgûl (1997) and Temple (1997).

Due to the work of Steve and Alan Freeman (1996 and Freeman 2017), longstanding enthusiasts for German rock music of the 1970s (for many years they have run the Ultima Thule distribution company and Audion magazine, both of which specialise in electronic, progressive and experimental music 
from Europe), the story has been fleshed out, not least to identify the 'Mad Twiddler' as Toby Robinson, a sound engineer who apparently did work with Stockhausen and the German rock groups Can and the Cosmic Jokers, and who was an engineer at Conny Plank's studio in the mid-1970s (Anon. 2009). (Subsequently, Alan Freeman (2012) claims that Robinson worked at Dieter Dierks' studio.)

The anonymous author of the liner notes to the 2009 CD reissue of what is alleged to be the original full album Orion Awakes by Golem (Anon. 2009) believes that sceptics viewed the Virgin releases as capitalising on the upsurge of interest in German rock music, due to the publication in 1995 of Julian Cope's Krautrocksampler and in 1996 of Steve and Alan Freeman's The Crack in the Cosmic Egg and Dag Erik Asbjørnsen's Cosmic Dreams at Play: A Guide to German Progressive and Electronic Rock. Whilst Cope does not mention Pyramid or any of the groups associated with it, the Freemans do have an entry for the label and for many of the groups. Asbjørnsen (1996) does not include them in his book, believing them to be fakes.

Our anonymous author goes on to argue that the obscurity of the groups and their releases is in large part due to the original records allegedly being pressed in 'limited runs of 100 copies (later said to be 25 copies)' (Anon. 2009). But the fact that no copies at all have surfaced adds weight to the sceptics' argument that this is a hoax (though Freeman (2012) claims to have seen an original Golem album for sale in Germany before the 1996 releases). The obscurity is not only explained, the liner notes continue, by the scarcity of 
the records, but also by the contractual obligations of the musicians involved. Only a few musicians have been identified as performing in previously known German groups of the era, such as Bernd Held (Birth Control) and Reinhard Karwatky (Dyzan). Perhaps most curious of all is the reference to Genius P. Orridge as a co-composer on the Golem tracks. The name is remarkably close to that of Genesis P-Orridge (Coum Transmissions, Throbbing Gristle, Psychic TV) and appears in Discogs as a pseudonym for Toby Robinson (though I can find no rationale for choosing the name).

The Discogs database is a useful source of discussion and contention around the Pyramid releases. The main page for the label Psi-Fi, which has released a number of albums by the Pyramid groups, states that the releases 'are generally considered a hoax', to which has been added 'These albums are no hoax, see my [Alan Freeman's] review below...'

(www.discogs.com/label/84972-Psi-Fi). Below the listings for the label we find a series of reviews, the earliest of which is dated 31 June 2012 and is written by Alan Freeman (2012). In it he mounts a strenuous defence for the authenticity of the label and the groups themselves, as recorded in Germany in the 1970s. His source appears unimpeachable: an interview with Toby Robinson, who also provides an appendix to Freeman's review (taken from Acme Records' discussion page, the label which re-released Golem's Orion Awakes in 2009), where he describes in some detail the recording processes, mentions some of those involved and notes his involvement as producer, musician and as the person who named the groups, all working 
pseudonymously ('because most of the studio time was purloined without the proprietor's knowledge'; ibid.).

For others, even an apparently first-hand account is not convincing. The absence of any physical evidence of the original releases remains a problem and some demand more rigorous proof: 'Seeing a copy in a shop ages ago is no evidence' ('bloop', 13 July 2012); 'Until solid irrefutable evidence is presented (actual copies of the LPs), the story must be considered at best a mystery and at worst an outright hoax' ('Alnjeyan', 15 July 2014). There is no listing on Discogs for any of the original Pyramid releases; only the 'reissues' are listed, adding weight to the sceptics' arguments that the history of production of the releases does not begin until the mid-1990s. Freeman (2012) suggests that some sceptics claim that the releases were made in the 1990s 'by people like Sun Dial and such like.' (Sun Dial are a British space rock group who, perhaps coincidentally, also recorded for Acme Records). 'Ashratom' (11 June 2015) finds the 1990s argument convincing and others also draw attention to what they hear as the presence of samplers, digital keyboards and drums 'with a very polished 90s sound' ('bloop', 13 July 2012). 'Bradx' (29 July 2015) finds the music on the Golem album 'much too studied, the production is too clean, the wah-wah too obvious and the drum sound is very modern.'

In countering the claim that before the 1996 releases, no one had been aware of the groups, proponents argue that the releases were made in 'dead' studio time, were the result of jam sessions by numerous musicians and only when 
there were sufficient pieces recorded would they be put together and issued as albums. In effect, the groups were fake groups, but the recordings were authentic, recorded in the mid-1970s. Specialist critics seem to agree. Ed Pinsent, editor of the Sound Projector magazine, states that the 'claim they must be 1990s hoaxes... is absurd.' Pinsent's argument does not appeal to historical data, nor to the sound of the recordings, but to the culture of collectors, who 'want to appropriate everything for themselves. However, such specialisation and selfishness is overturned by democratising releases like this' (cited in Anon. 2009). For Pinsent, it is the very obscurity of the recordings, brought to light by a major record label some twenty years after their initial release, that convinces him of their authenticity. Moreover, to those sceptics who argue that the recordings do not seem to fit with the admittedly broad scope of German rock music of the time, Pinsent argues that the notion of a 'Krautrock continuum' is misplaced, and that 'oddities' such as the Pyramid releases 'confound lazy journalists who think they've got the scene all figured out' (ibid.).

'Bradx' (29 July 2015) writes that 'The music's quite good on some of these... but I find it very hard to swallow the back-story.' On other discussion sites, however, we find more enthusiastic assessments of the music. The Mutant Sounds blog discussion of the Pyramid releases privileges musical quality over origin (at mutant-sounds.blogspot.co.uk/2007/12/ultimate-spinach-mindflowers.html): 
Musically speaking though, some of them are great albums, with the Nazgûl... leading the lot.

('mutantsounds' citing 'spacefreak', 8 December 2007)

Joining the discussion, 'spacefreak' draws our attention to other fake albums in similar vein, including Damenbart's Impressionen '71, purporting to be an early 1970 s German obscurity but recorded in 1989 and the similarly subtitled Mitte/winternacht 1971, released on an obscure British label (Betley Welcomes Careful Drivers), probably in the 1990s. Spacefreak considers these and similar releases whose history of production has been shown to be fake, as in the case of Masayo Asahara's two releases on Martin Archer's Discus Records that, far from being 'drone-prog-jazz' obscurities recorded in the 1970s in Japan, are twenty-first century recordings by Archer himself. The argument here is that such releases differ from the Pyramid catalogue as the revealed or acknowledged fakeness of the former sets them apart as particular kinds of fake that can be understood as

tributes where trickery works as a game to perplex the listener and hook him up to the music by setting the appropriate climate, and not affairs to cash [in] on massive, stylistic revivals.

('spacefreak', 8 December 2007)

'In the end', though, 'spacefreak' concludes, 'it's the music that counts and some contained in them [the recordings] is undoubtedly great' (ibid.) 
In addition to addressing the authenticity of the album and the other Pyramid releases, Rate Your Music's reviewers of Golem's Orion Awakes (rateyourmusic.com//release/album/golem_f3/orion_awakes) mostly praise the music, whilst remaining aware of the controversy over its provenance:

Even if it is a fake, the album is pretty awesome.

('scannerhead', 3 October 2011)

This is amazing shit regardless of its release date.

('nightwrath', 7 August 2009)

It's probably a fake but if so it's a great one... All in all a very good album and what the hell, l'll give it the benefit of the doubt and add it to my favourite krautrock albums list.

('hellaguru', 13 April 2016)

Of all the Pyramid/Psi-Fi albums I've heard so far, this is one of the more blatantly fishy. It's also one of the best, by miles. If you'd released this [i.e., in 1996] as a group of UK musicians doing a brilliant combination of Motorik beats and Hawkwind-y heavy exploration, it'd still be talked about today. Instead, someone had to invent a mythology that's only confused things.

('thrasher2809', 23 January 2016) 
Some reviewers do not engage with arguments over origin at all, preferring simply to judge the music as exemplary of its genre: 'a dark heavy and psychedelic rock gem' ('soundexpector', 22 October 2011). The Rate Your Music comments begin in 2006 and span more than ten years. Twenty years after the Unknown Deutschland series first appeared, listeners, collectors and critics still find the aetiology of a set of obscure recordings aesthetically, ethically and culturally significant, even when they appear to be ignoring the history of production.

\section{Finding the authentic in the inauthentic}

Cases such as the Residents and the Unknown Deutschland series seem to take us far from Moore's and Behr's modes of authenticity, not least because the origin of the voices presented in the recordings are open to dispute. It is not simply that the voices are anonymous or pseudonymous, but that the critical discourses surrounding them are unstable. The confusion of discourses, including those of the alleged originators of the music as well as those of critics and fans, refuses to settle the context that is crucial to Moore's argument for communicative integrity. In the case of the Residents, a context is deliberately and self-consciously established by the artists claiming to be the Residents that makes it impossible to determine who is communicating what and why. Whilst it is truistic to say that all art relies on interpretation to some degree, when we approach the Residents the absence of any coherent aetiology throws us back fully on interpretation. Only those with access to the group as 'real' people are able to join interpretation with an assessment of the 
group's integrity, which is what makes Chris Cutler's argument- that behind the fakery lies a very serious project-so powerful.

But we might see how Moore's triumvirate of integrity, sincerity and honesty is played out by the Residents even without Cutler's privileged access. Though lacking the directness of communication, the personal transmission of experience or the 'truth' that may issue from a folk-like performance, the longevity and consistency of the Residents suggests a practice that is intended to have meaning beyond the practice of fakery. The group's cynicism towards the entertainment industry, their satires on commercialism (both musical and strategic, through advertising campaigns such as their invitation to 'Buy or Die!') can itself be considered as an ethical practice with aesthetic outcomes. In this respect, their authenticity (if we may call it that) is not weakened by their reliance on fake personae and false histories of production, but instead is strengthened by them. If the Residents are communicating anything about popular culture, we might argue, it is achieved through a vehicle that itself is emblematic of that communication, a vehicle that does not rely on the adoption of the more traditional modes of communication that Moore finds to be dominant in rock music.

The use of cynicism and its close relation, irony, is not new in popular music. Lindberg et al. and Moore draw our attention to the work of musicians such as David Bowie, Bryan Ferry and Elvis Costello, all of whom use irony, often in the form of pastiche or parody, for apparently sincere and serious ends. In their deployment of intertextuality, borrowing from multiple musical and lyrical 
sources, Moore (2001, p. 201) finds in their work an 'assumption of postmodern presence' that argues against notions of the authentic as conventionally understood. As we have seen, though, in the case of the Residents and, arguably, the Unknown Deutschland recordings, postmodernism is not merely identifiable as a stylistic sheen but may be understood as an engine of creativity which, in an extreme cultural context such as that generated by the Residents, might render arguments over authenticity irrelevant. A postmodern presence, though, as Grossberg (1992, p. 589) argues, does not prevent engagement in the music by listeners: it 'still produces real and significant differences for its fans.' We may therefore argue that even in such apparently inauthentic performances authenticity might be found through listeners' interpretations of the performance as serious. Or rather, as Lindberg et al. put it:

insofar as listeners reconstruct the author's intentions as serious, as in a conversation, this explains why even clearly "artificial", ironic or parodying acts may be found "authentic".

(Lindberg et al. 2005, p. 45)

To be taken seriously need not entail conformity to dominant communicative conventions. Of course, the techniques employed by such as Bowie, Ferry and Costello have themselves become conventions and, after all, their modes of address and the modes proposed by Moore and Behr are all to some degree constructions, performances of personae. Frith's (1996, p. 71) discussion of Eurodisco concludes that authenticity lies not in the history of 
production but in a 'perceived quality of sincerity and commitment' (my emphasis). The Residents develop the notion of constructedness in popular music to an excessive degree and in doing so show how it might still be possible to present music that demonstrates integrity, sincerity and honesty under the most unusual conditions.

The case of Unknown Deutschland and the Pyramid groups is quite different. Here the (alleged) history of production is key to the reception of the music as an indicator of the original or faked nature of the groups and their music. We can identify three aesthetic positions within the critical reception of the Pyramid groups. The first is convinced by the aetiology of the record label, the groups and their music. There is no doubt that all are genuine and that any reasons for anonymity or pseudonymity are for contractual reasons. It is important, though, for advocates of this position to engage with the arguments of their opponents and to find reasons for the absence of any original copies of the records (editions were very small). Advocates treat the expertise of the Freeman brothers as beyond reproach and their accounts, together with Toby Robinson's, as truth statements. Returning to Janaway's discussion of origins, proponents find the story both 'interesting and plausible.' From this position it becomes possible to place the recordings within a broader history of German rock music in the 1970s. The unusual and at times atypical styles presented in the Unknown Deutschland series and the subsequent singlegroup releases become evidence for a richer, more diverse musical landscape than dominant histories of 'Krautrock' have presented. 
The second position opposes this view and believes the recordings and the circumstances that gave rise to them to be fictitious. There is no need for advocates of this position to engage in arguments about sincerity of intent; the ethical argument over aetiology, that the entire project is fake because the history of production is false, is sufficient to dismiss the entire class of recordings as products of Germany in the 1970s. This second position, however, does not seem to be held in isolation from a third position, one that finds aesthetic value in the music at the same time that it dismisses the arguments over the authenticity of the production history of the recordings, their 'original' release and their personnel. This last position is not coloured by ethical concerns over integrity and honesty: it is interested in the music, finding in it a value that does not need to proceed from a given or accepted history. The critical reception in this hybrid position has no need for aetiological considerations, save to reject them in favour of an argument that places the music not in a specific history but in a broader context of generic comparison.

Though disbelieving of the given history, fans are still able to hear the music as a species of German rock music (Krautrock, Motorik), as well as participating in a variety of broader generic labels (psychedelic, heavy). Nevertheless, it seems that fans have to take account of the supposed history of production; its presence has to be confronted and dispensed with before they are able to engage with the music evaluatively. An entire history of production is rejected as inauthentic, which defines the work as fake. Yet, even in the absence of any alternative history of production through which we 
might judge the integrity of a performance, it remains possible to consider a musical performance as authentic in respect of its aesthetic value, separately from any ethical judgement.

In a footnote to his discussion of the musical forgery, Janaway $(1999$, p. 62) refers briefly to the notion of an 'inventive forgery', where a newly-written composition is passed off as an unknown work by an already-known composer. But even if we do not find the history of the Unknown Deutschland recordings credible, they do not properly fit into this category, except in a weak sense, to the extent that some of them allegedly contain performances by a small number of known musicians working pseudonymously. The term remains an appealing one, however, not least because it suggests that, as the critical reception of even the most sceptical of fans shows, where a work is considered a fake it can be positively evaluated as an aesthetic success. A given history of production, whether true or false, need not interfere with the aesthetic experience of listeners, though it might interfere with specific aesthetic claims, such as 'this music is significant because of its specific history of production.' Rather than the 'inventive forgery' we might posit the notion of the 'productive fake', one that is able to generate significant critical engagement by listeners and to find itself culturally valued due to that engagement, rather than due to any aetiological claims made on its behalf.

\section{Bibliography}

Anon. 2009. Liner notes to Golem, Orion Awakes. Acme Records/Lion

Productions. ACLN 1014CD. 
Asbjørnsen, D. E. 1996. Cosmic Dreams at Play: A Guide to German

Progressive and Electronic Rock (London: Borderline Productions)

Barker, H. and Y. Taylor. 2007. Faking It: The Quest for Authenticity in Popular Music. (London: Faber and Faber)

Beebe, R., D. Fulbrook and B. Sanders. 2002. 'Introduction', Rock Over the Edge: Transformations in Popular Music Culture. (Durham, North Carolina and London: Duke University Press), pp. 1-21

Behr, A. 2015. 'Join together with the band: Authenticating collective creativity in bands and the myth of rock authenticity reappraised', Rock Music Studies, 2(1), pp. 1-21

Cope, J. 1995. Krautrocksampler: One Head's Guide to the Great Kosmische Musik - 1968 Onwards. (Yatesbury: Head Heritage)

Cutler, C. 1985. File under Popular. (London: November Books)

Freeman, A. 2012. 'Alan Freeman here, co-author of The Crack In The Cosmic Egg'. www.discogs.com/label/84972-Psi-Fi. Accessed 6 July 2017.

Freeman, A. 2017. Liner notes to Cozmic Corridors, Cozmic Corridors. Mental Experience MENT011 LP. 2017 
Freeman, S. and A. Freeman. 1996. The Crack in the Cosmic Egg: Encyclopedia of Krautrock, Kosmische Musik and Other Progressive, Experimental and Electronic Musics from Germany (Leicester: Audion)

Frith, S. 1983. Sound Effects: Youth, Leisure and the Politics of Rock (London: Constable)

Frith, S. 1996. Performing Rites: Evaluating Popular Music (Oxford: Oxford University Press)

Goodman, N. 1968. Languages of Art: An Approach to a Theory of Symbols (Indianapolis: Bobbs-Merrill)

Grossberg, L. 1992. 'Is there a fan in the house? The affective sensibility of fandom', in The Adoring Audience, ed. L. A. Lewis (London: Routledge), pp. $581-590$

Janaway, C. 1997. 'Two kinds of artistic duplication', British Journal of Aesthetics, 37(1), pp. 1-14

Janaway, C. 1999. 'What a musical Forgery isn't', British Journal of Aesthetics, 39(1), pp. 62-71

Lefebvre, S. 2017. 'Eye-dentity politics', The Wire (398), April, pp. 38-43 
Lindberg, U. et al. 2005. Rock Criticism from the Beginning: Amusers, Bruisers, and Cool-headed Cruisers (New York: Peter Lang)

McLeod, K. 2001. '*1/2: A critique of rock criticism in North America', Popular Music, 20(1), pp. 47-60

Manwaring, T. 1996. Liner notes to Unknown Deutschland: The Krautrock Archive, Volume 1. Virgin Records CDOVD468.

Moore, A. F. 2001. Rock: The Primary Text-Developing a Musicology of Rock. 2nd ed. (Aldershot: Ashgate)

Shirley, I. 2015. Never Known Questions: Five Decades of the Residents (London: Cherry Red Books)

Smith, S. 2001. In the Court of King Crimson. (London: Helter Skelter)

Steele, H. 1977. 'Fakes and forgeries', British Journal of Aesthetics, 17(3), pp. 254-258

Visconti, T. 2012. 'Thin Lizzy: Live and Dangerous', 9 March. www.tonyvisconti.com/artists/thinlizzylive.htm. Accessed: 10 July 2017 
Walser, R. 1993. Running with the Devil: Power, Gender, and Madness in Heavy Metal Music (Hanover, New Hampshire: Wesleyan University Press)

\section{Discography}

Chou Pahrot, Live. Klub Records. KLP 19. 1979

Cozmic Corridors, Cozmic Corridors. Mental Experience. MENT011 LP. 2017

John Fahey, Blind Joe Death. Takoma Records. K80P-4447/8. 1959

Golem, Orion Awakes. Psi-Fi. PSCD0003. 1996

King Crimson, Starless and Bible Black. Island. ILPS 9275. 1974

The Nazgûl, The Nazgûl. Psi-Fi. PSCD0005. 1997

The Residents, Meet the Residents. Ralph Records. RR0274. 1974

The Residents, Not Available. Ralph Records. RR1174. 1978

The Seeds, Merlin's Music Box: The Seeds in Concert. GNP Crescendo.

GNPS-2043. 1968

Thin Lizzy, Live and Dangerous. Vertigo. 6641807.1978 
Frank Zappa, Weasels Ripped My Flesh. Bizarre. MS 2028. 1970

Various artists, Unknown Deutschland: The Krautrock Archive, Volumes 1, 2 and 3. Virgin Records. CDOVD468, CDOVD472 and CDOVD473. 1996 